\title{
Crystal Structure of Bis(acetone- $\mathrm{KO}$ )-1,4,8,11-tetraazacyclotetradecane Copper(II) Ditetraphenylborate Acetone Disolvate
}

\author{
Chihiro Matsui,* Toru OKawara, ${ }^{* * \dagger}$ Toshihiko Nagamura, ${ }^{* *}$ and Kenji TaKehara**† \\ * Materials Science and Chemical Engineering Advanced Course, National Institute of Technology, Kitakyushu \\ College, Shi-i 5-20-1, Kokuraminami-ku, Kitakyushu, Japan 802-0985 \\ **Department of Creative Engineering, National Institute of Technology, Kitakyushu College, Shi-i 5-20-1, \\ Kokuraminami-ku, Kitakyushu, Japan 802-0985
}

\begin{abstract}
The solid-state structure of bis(acetone- $\kappa O)$-1,4,8,11-tetraazacyclotetradecane copper(II) ditetraphenylborate acetone disolvate was determine by single-crystal X-ray diffraction analysis. Single crystals of the title compound were obtained from acetone and diethyl ether. The compound crystallizes in a triclinic system, space group $P 1$. The unit-cell parameters were determined to be $a=12.2123(15), b=12.5684(16), c=12.9841(16) \AA, \alpha=100.526(2)^{\circ}, \beta=$ $107.4237(19)^{\circ}, \gamma=116.1558(19)^{\circ}, Z=1, V=1587.4(3) \AA^{3}$. The crystal includes two acetone molecules. One of which shows a conformational disorder. The crystal structure was solved by dual space methods and refined by full-matrix least-squares on $F^{2}$ to final values of $R 1=0.0392$ and $w R 2=0.0999$ for $I>2 \sigma(I)$ and all data, respectively.
\end{abstract}

(Received July 15, 2015; Accepted August 8, 2015; Published on web October 10, 2015)

Copper(II) complexes of macrocyclic ligands have been extensively studied because of their application for magneticresonance imaging and positron-emission tomography. ${ }^{1-3}$ Among the macrocyclic ligands, 1,4,8,11-tetraazacyclotetradecane, which is also known as cyclam, is often used as a four-coordinate ligand. Thus, understanding how the copper complexes behave in a living cell is the first concern for the chemistry of bioimaging. To the best of our knowledge, copper cyclam complexes having aldehydes or ketones as their axial ligands have rarely been reported, despite their biological importance and structural interests. Here we report on the crystal structure of a copper cyclam complex bearing acetone ligands.

In our present research, the copper(II) complex was prepared from 1,4,8,11-tetraazacyclotetradecane $(0.50 \mathrm{mmol}, 100 \mathrm{mg})$ and copper(II) sulfate pentahydrate $(0.50 \mathrm{mmol}, 126 \mathrm{mg})$, which were dissolved in water $(10 \mathrm{~mL})$ and heated to $100^{\circ} \mathrm{C}$ for 20 min. The solution color turned to purple during the reaction. After the reaction, sodium tetraphenylborate $(3.0 \mathrm{mmol}, 1.03 \mathrm{~g}$ ) was added to the solution to form a precipitate of the

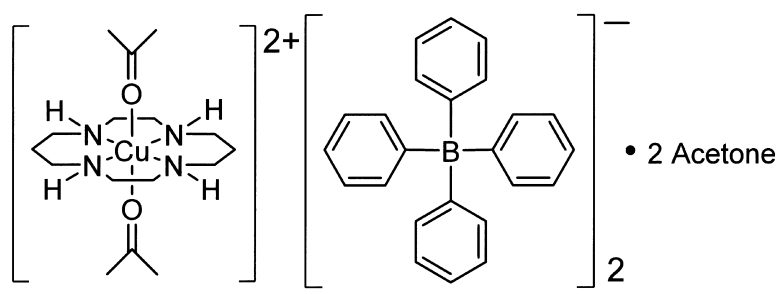

Fig. 1 Chemical diagram of the title compound.

$\dagger$ To whom correspondence should be addressed.

E-mail: T. Okawara (E-mail: okawara@kct.ac.jp), K. Takehara (E-mail: takehara@kct.ac.jp) tetraphenylborate salt. The precipitate was collected by filtration and dried in vacuo. To obtain single crystals suitable for X-ray crystallography, a light-purple powder was dissolved in the least amount of acetone and placed in a glass bottle, which served diethyl ether separately. Purple needle-shaped crystals, which were $1 \mathrm{~mm}$ wide, $10 \mathrm{~mm}$ long, and $1 \mathrm{~mm}$ thick, could be obtained within one week (Fig. 1, $0.41 \mathrm{mmol}, 468 \mathrm{mg}$, $82 \%$ yield).

$\mathrm{X}$-ray crystallography was performed at $100 \mathrm{~K}$ on a Bruker

Table 1 Crystal and experimental data

Chemical formula: $\mathrm{C}_{70} \mathrm{H}_{88} \mathrm{~B}_{2} \mathrm{CuN}_{4} \mathrm{O}_{4}$

Formula weight $=1134.60$

$T=100 \mathrm{~K}$

Crystal system: triclinic $\quad$ Space group: $P 1$

$a=12.2123(15) \AA \quad \alpha=100.526(2)^{\circ}$

$b=12.5684(16) \AA \quad \beta=107.4234(19)^{\circ}$

$c=12.9841(16) \AA \quad \gamma=116.1558(19)^{\circ}$

$V=1587.4(3) \AA^{3} \quad Z=1$

$D_{\text {calcd }}=1.187 \mathrm{~g} / \mathrm{cm}^{3}$

$\mu\left(\right.$ Mo $\left.K_{\alpha}\right)=0.394 \mathrm{~mm}^{-1} \quad F(000)=607$

Crystal size $=0.16 \times 0.24 \times 0.60 \mathrm{~mm}^{3}$

Number of reflections collected $=11074$

Number of independent reflections $=9103$

$2 \theta$ range for data collection: 5.485 to $61.66^{\circ}$

Data/Restraints/Parameters $=9103 / 76 / 792$

Goodness-of-fit on $F^{2}=1.039$

$R$ indices $[I>2 \sigma(I)]: R 1=0.0392, w R 2=0.0941$

$R$ indices (all data): $R 1=0.0471, w R 2=0.0999$

$(\Delta / \sigma)_{\max }=0.004$

$(\Delta \rho)_{\max }=0.492 \mathrm{e}^{-3} \quad(\Delta \rho)_{\min }=-0.601 \mathrm{e}^{-3}$

Measurement: Bruker Smart APEX CCD diffractometer Program system: SHELXTL

Structure determination: Dual-space methods (SHELXS-97)

Refinement: full matrix least-squares (SHELXL-97)

CCDC deposition number: 1411604 
Table 2 Selected bond lengths and angles

\begin{tabular}{|c|c|c|c|}
\hline \multicolumn{2}{|c|}{ Distances $[\AA]$} & \multirow{2}{*}{\multicolumn{2}{|c|}{ Angles $\left[{ }^{\circ}\right]$}} \\
\hline \multicolumn{2}{|c|}{$\mathrm{Cu}-\mathrm{X}$} & & \\
\hline Cu1-N1 & $2.038(5)$ & N1-Cu1-N2 & $86.2(3)$ \\
\hline $\mathrm{Cu} 1-\mathrm{N} 2$ & $2.016(6)$ & N1-Cu1-N3 & $179.4(4)$ \\
\hline $\mathrm{Cu} 1-\mathrm{N} 3$ & $2.001(7)$ & N1-Cu1-N4 & $94.6(3)$ \\
\hline $\mathrm{Cu} 1-\mathrm{N} 4$ & $1.998(7)$ & N2-Cu1-N3 & 93.3(3) \\
\hline $\mathrm{Cu} 1-\mathrm{O} 1$ & $2.481(5)$ & N2-Cu1-N4 & $179.0(4)$ \\
\hline $\mathrm{Cu} 1-\mathrm{O} 2$ & $2.492(5)$ & N3-Cu1-N4 & $85.9(3)$ \\
\hline \multicolumn{2}{|c|}{$\mathrm{C}=\mathrm{O}$} & Cu1-O1-C11 & 173.3(6) \\
\hline $\mathrm{O} 1-\mathrm{C} 11$ & $1.215(9)$ & & \\
\hline $\mathrm{O} 2-\mathrm{C} 14$ & $1.212(8)$ & & \\
\hline O3-C17 & $1.195(10)$ & & \\
\hline $\mathrm{O} 4 \mathrm{~A}-\mathrm{C} 20 \mathrm{~A}$ & $1.237(15)$ & & \\
\hline O4B-C20B & $1.231(18)$ & & \\
\hline
\end{tabular}

SMART APEX diffractometer using graphite monochromated Mo- $K_{\alpha}$ radiation with a CCD detector. The data frames were obtained by $\Phi$ and $\omega$ scans with an exposure time of $3.0 \mathrm{~s}$ per a frame. The crystallographic data and selected geometrical parameters are summarized in Tables 1 and 2. The structure was solved by dual space methods and refined by full-matrix least-square methods. The title compound crystalized in a triclinic system with space group $P 1$. The refinement did not converged when the centrosymmetric space group was applied. Although the Flack parameter was still large (0.17(3)), the inverted structure of the compound showed the parameter of nearly 1.0, indicating that the absolute structure is reliable. Hydrogen atoms, except on nitrogen atoms, were placed at the calculated position and ride on their parent atoms. The hydrogen atoms attached to the nitrogen atoms were found in a difference Fourier map. For a stable refinement, some restraints were applied to the refinement of the anisotropic displacement parameters of non-hydrogen atoms. The detailed crystallographic analysis is available in the Supporting Information.

An ORTEP view of the title compound is displayed in Fig. 2. In the crystal structure, there are three features to be mentioned: firstly, two acetone ligands occupy axial coordination site of the copper(II) center to form a distorted octahedral structure; secondly, two additional acetone molecules are trapped in a hydrophobic pocket surrounded by tetraphenylborate; thirdly, the cyclam ligand coordinates to the copper(II) center to form a square-planar geometry. Two acetone molecules are located at the axial positions of the copper(II) complex with $\mathrm{Cu}-\mathrm{O}$ distances of 2.481(5) and 2.492(5) $\AA$ for $\mathrm{Cu} 1-\mathrm{O} 1$ and $\mathrm{Cu} 1-\mathrm{O} 2$, respectively. The bond angles between $\mathrm{Cu}-\mathrm{O}-\mathrm{C}$ are 173.3(6) and $176.6(6)^{\circ}$ for $\mathrm{Cu} 1-\mathrm{O} 1-\mathrm{C} 11$ and $\mathrm{Cu} 1-\mathrm{O} 2-\mathrm{C} 14$, respectively. Although these values are longer than the sum of their radii $(0.87 \AA$ for a six-coordinated divalent copper and $1.52 \AA$ for the van der Waals radius of oxygen), ${ }^{4}$ the values are still comparable with a previously reported bis(acetone)bis(ethylenediamine) copper(II) complex and a diaqua(cyclam)copper(II) complex. ${ }^{5,6}$ The $\mathrm{C}=\mathrm{O}$ distances are quite similar among the axial and free acetone molecules.

Second, two additional acetone molecules are located at hydrophobic pockets that are formed by phenyl groups of the tetraphenylborate anions. The methyl groups of the acetone molecules face to the phenyl groups and interact through the $\mathrm{CH}-\pi$ type interaction. At the same time, the oxygen atoms $(\mathrm{O} 3$

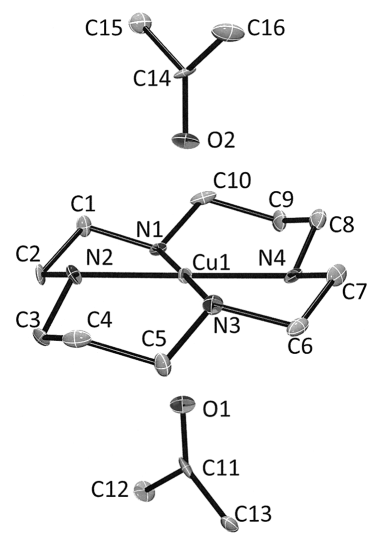

Fig. 2 ORTEP drawing of the cationic part of the title compound The thermal ellipsoids were drawn at the $50 \%$ probability level. Hydrogen atoms were omitted for clarity.

and $\mathrm{O} 4 \mathrm{~A}$ ) form $\mathrm{NH} \cdots \mathrm{O}$ hydrogen bonding with $\mathrm{N}-\mathrm{O}$ distances of 3.067(7) and 3.18(2) $\AA$. Moreover, one of the trapped solvent molecule splits into Acetone A, which consist of O4A, C20A, $\mathrm{C} 21 \mathrm{~A}$, and $\mathrm{C} 22 \mathrm{~A}$, and Acetone B, which consist of O4B, C20B, $\mathrm{C} 21 \mathrm{~B}$, and $\mathrm{C} 22 \mathrm{~B}$, probably due to a large pocket size. The occupancy values of the two molecules were found to be $60 \%$ and $40 \%$, respectively.

The cyclam ligand captures the copper(II) ion to form a trans III conformation. The nitrogen atoms coordinate to the copper center with $\mathrm{Cu}-\mathrm{N}$ distances of 2.038(5), 2016(6), 2.001(7), and

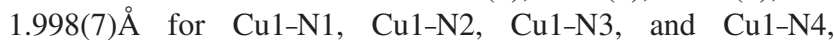
respectively, and form a square-planar $\mathrm{N} 4$ structure. The average deviations of the nitrogen atoms from the N4 mean plane is $0.008 \AA$, showing that the cyclam ligand takes the form of the square-planar conformation. In the single crystal, the cyclam ligand adopts a trans III (RRSS) conformation, which is known to be the most common conformation of the ligand.

\section{Acknowledgements}

This work has been partially supported by Grant-in-Aid for Young Scientists B No. 15K17848 from the Ministry of Education, Culture, Sports, Science and Technology (MEXT) and Nanotechnology Platform No. NPS13103 from MEXT. The authors appreciate Prof. Dr. Yoshio Hisaeda and Prof. Dr. Toshikazu Ono in Kyushu University for concerning the X-ray measurement.

\section{References}

1. J. Li, Y. Zhu, S. T. Hazeldine, S. M. Firestine, and D. Oupický, Biomacromolecules, 2012, 13, 3220.

2. M. Yu, J. R. Price, P. Jensen, C. J. Lovitt, T. Shelper, S. Duffy, L. C. Windus, V. M. Avery, P. J. Rutledge, and M. H. Todd, Inorg. Chem., 2011, 50, 12823.

3. E. Boros, E. Rybak-Akimova, J. P. Holland, T. Rietz, N. Rotile, F. Blasi, H. Day, R. Latifi, and P. Caravan, Mol. Pharmaceutics, 2014, 11, 617.

4. P. Enghag, "Encyclopedia of the Elements", Wiley-VCH, Weinheim, 2004

5. T. Akitsu and Y. Einaga, Acta Cryst., 2004, C60, m162.

6. N. S. Ahmad Tajidi, N. Abdullah, Z. Arifin, K. W. Tan, and S. W. Ng, Acta Cryst., 2010, E66, m887.

7. J. Schneider, H. Jia, J. T. Muckermana, and E. Fujita, Chem. Soc. Rev., 2012, 41, 2036. 